\title{
Quantification of Regional Ozone Pollution Characteristics and Its Temporal Evolution: Insights from Identification of the Impacts of Meteorological Conditions and Emissions
}

\author{
Leifeng Yang ${ }^{1}\left(\mathbb{D}\right.$, Danping Xie ${ }^{1, *}$, Zibing Yuan ${ }^{2}$, Zhijiong Huang ${ }^{3}$, Haibo Wu ${ }^{4}$, Jinglei Han ${ }^{1}$, Lijun Liu ${ }^{1}$ \\ and Wenchao Jia ${ }^{1}$ \\ 1 South China Institute of Environmental Sciences, Ministry of Ecology and Environment, \\ Guangzhou 510655, China; yangleifeng@scies.org (L.Y.); hanjinglei@scies.org (J.H.); \\ liulijun@scies.org (L.L.); jiawenchao@scies.org (W.J.) \\ 2 School of Environment and Energy, South China University of Technology, Guangzhou 510006, China; \\ zibing@scut.edu.cn \\ 3 Institute for Environmental and Climate Research, Jinan University, Guangzhou 511443, China; \\ bmmj@163.com \\ 4 Customer Service Center, China Southern Power Grid, Guangzhou 510620, China; haibowu2021@163.com \\ * Correspondence: xiedanping@scies.org
}

check for updates

Citation: Yang, L.; Xie, D.; Yuan, Z.; Huang, Z.; Wu, H.; Han, J.; Liu, L.; Jia, W. Quantification of Regional Ozone Pollution Characteristics and Its Temporal Evolution: Insights from Identification of the Impacts of Meteorological Conditions and Emissions. Atmosphere 2021, 12, 279. https://doi.org/10.3390/ atmos12020279

Academic Editor: Martin Dameris

Received: 24 January 2021

Accepted: 15 February 2021

Published: 20 February 2021

Publisher's Note: MDPI stays neutral with regard to jurisdictional claims in published maps and institutional affiliations.

Copyright: (c) 2021 by the authors. Licensee MDPI, Basel, Switzerland. This article is an open access article distributed under the terms and conditions of the Creative Commons Attribution (CC BY) license (https:/ / creativecommons.org/licenses/by/ $4.0 /)$.

\begin{abstract}
Ozone $\left(\mathrm{O}_{3}\right)$ pollution has become the major new challenge after the suppression of $\mathrm{PM}_{2.5}$ to levels below the standard for the Pearl River Delta (PRD). $\mathrm{O}_{3}$ can be transported between nearby stations due to its longevity, leading stations with a similar concentration in a state of aggregation, which is an alleged regional issue. Investigations in such regional characteristics were rarely involved ever. In this study, the aggregation (reflected by the global Moran's I index, GM), its temporal evolution, and the impacts from meteorological conditions and both local (i.e., produced within the PRD) and non-local (i.e., transported from outside the PRD) contributions were explored by spatial analysis and statistical modeling based on observation data. The results from 2007 to 2018 showed that the GM was positive overall, implying that the monitoring stations were surrounded by stations with similar ozone levels, especially during ozone seasons. State of aggregation was reinforced from 2007 to 2012, and remained stable thereafter. Further investigations revealed that GM values were independent of meteorological conditions, while closely related to local and non-local contributions, and its temporal variations were driven only by local contributions. Then, the correlation $\left(\mathrm{R}^{2}\right)$ between $\mathrm{O}_{3}$ and meteorology was identified. Result demonstrated that the westerly belonged to temperature (T) and surface solar radiation (SSR) sensitive regions and the correlation between ozone and the two became intense with time. Relative humidity $(\mathrm{RH})$ showed a negative correlation with ozone in most areas and periods, whereas correlations with $\mathrm{u}$ and v were positive for northerly winds and negative for southerly winds. Two important key points of such investigation are that, firstly, we defined the features of ozone pollution by characterizing the temporal variations in spatial discrepancies among all stations, secondly, we highlighted the significance of subregional cooperation within the PRD and regional cooperation with external environmental organizations.
\end{abstract}

Keywords: ozone; aggregation; meteorological; spatial autocorrelation; Moran's I; spatiotemporal evolution; Pearl River Delta

\section{Introduction}

The Pearl River Delta (PRD), the largest city cluster in South China, has long suffered from severe air pollution due to rapid urbanization and intensive anthropogenic activities. Following the introduction of a series of stringent air pollution control measures, levels of most atmospheric pollutants in the PRD, such as $\mathrm{SO}_{2}, \mathrm{NO}_{\mathrm{x}}, \mathrm{CO}, \mathrm{PM}_{10}$, and $\mathrm{PM}_{2.5}$, have gradually decreased in recent years; however, tropospheric ozone $\left(\mathrm{O}_{3}\right)$ is the exception and it became the primary pollutant since 2015 and the amount of days exceeding the 
standard $\left(160 \mu \mathrm{g} / \mathrm{m}^{3}\right)$ is far more than the other two regions [1-3]. After suppressing $\mathrm{PM}_{2.5}$ to levels below the standard concentration, the PRD will now focus on ozone control. $\mathrm{As}_{3}$ is relatively persistent, it can be transported between adjacent areas, and therefore $\mathrm{O}_{3}$ concentrations at different stations within small areas approach similar levels. Such aggregated distributions can provide insight into the interactions within a small area. However, such investigations, especially quantification of the aggregated distribution, have not been discussed in detail in previous studies.

$\mathrm{O}_{3}$ is formed by the photochemical reaction of the precursors $\mathrm{NO}_{\mathrm{x}}$ and volatile organic compounds (VOCs) under the action of sunlight $[4,5]$. The relationships between $\mathrm{O}_{3}$ formation and its precursors are highly nonlinear and have been investigated in detail based on observations or simulations [6-10]. Generally, $\mathrm{O}_{3}$ formation is sensitive to VOCs in urban areas and to $\mathrm{NO}_{x}$ in suburban or rural areas [10-12]. $\mathrm{O}_{3}$ formation has become less VOC-limited due to the substantial reductions in $\mathrm{NO}_{\mathrm{x}}$ in urban areas, and there have been several related investigations in the PRD [10,13-16].

$\mathrm{O}_{3}$ concentrations are related to meteorological conditions [17,18], local production [6,19-21], and long-range non-local transport from outside the local area [22-25]. Several different methods based on simulation models or observations have been used to investigate the influence of these factors $[9,24,26,27]$. Photochemical reaction rate, precursor emission rate, and transportation of $\mathrm{O}_{3}$ and its precursors are affected by meteorological conditions directly or indirectly. Due to differences in meteorological conditions and precursor emission levels at the various stations, the correlations between $\mathrm{O}_{3}$ concentrations and meteorology vary considerably. Previously, we investigated the long-term effects on $\mathrm{O}_{3}$ levels in the PRD of local and non-local $\mathrm{O}_{3}$ production, differences in meteorological conditions, and differences in precursor emission levels [28]. We concluded that meteorological conditions suppressed $\mathrm{O}_{3}$ increases over the long-term, and local emissions showed different impacts in the northeastern and southwestern of PRD, while non-local sources had similar impacts on the whole area. However, there has been insufficient investigation into the relationships between $\mathrm{O}_{3}$ and meteorological conditions in the perspective of space, especially the long-term spatiotemporal evolution.

Meteorological variables, such as solar radiation, can control the photochemical reaction and affect net $\mathrm{O}_{3}$ production directly, while high temperatures are conducive to $\mathrm{O}_{3}$ production by increasing emission of natural sources biogenic volatile organic compounds (BVOCs), hydroxyl radical $(\mathrm{OH})$ concentrations in the atmosphere, and decomposition of peroxyacetyl nitrate (PAN) [29-31]. High $\mathrm{O}_{3}$ concentrations are commonly accompanied by high temperatures, high levels of solar radiation, low relative humidity, and weak winds [32-34]. Areas with similar variations in $\mathrm{O}_{3}$ and meteorological conditions are likely to have similar sensitivity to meteorological conditions. This provides a straightforward approach to infer the relationships between $\mathrm{O}_{3}$ and meteorological conditions.

Generally, stations with impacts from local sources are likely to have discrete geographic distributions because of the heterogeneous local emission levels at the different stations, compared with the case of non-local impacts that result from $\mathrm{O}_{3}$ transport by largescale prevailing winds are removed. Such non-local contribution result in more uniform $\mathrm{O}_{3}$ concentrations at the different stations. Thus, the aggregated distribution of stations affected by local impacts will be strengthened when non-local sources are added. It is unclear whether the aggregation is affected by meteorological conditions, although areas with high precursor levels are more sensitive to meteorological variations [35]. $\mathrm{O}_{3}$ concentrations can be reinforced or weakened by meteorological conditions depending on the mechanisms of $\mathrm{O}_{3}$ formation and transport into or out of the area of the station. Over the long term, the temporal evolution of such aggregation of $\mathrm{O}_{3}$, the roles of meteorological conditions, local and non-local contribution on the aggregated distribution of stations were hardly noted.

In this study, we used spatial analysis based on observation data of the PRD to quantify the extent of aggregation of $\mathrm{O}_{3}$. The temporal evolution of $\mathrm{O}_{3}$ from 2007 to 2018 and the driving factors were then identified. Finally, the spatiotemporal evolution of 
correlations between $\mathrm{O}_{3}$ and meteorological conditions was examined. These investigations characterize $\mathrm{O}_{3}$ pollution and facilitate its control.

\section{Data and Methods}

\section{1. $\mathrm{O}_{3}$ and Meteorological Data Sets}

Maximum daily 8-h moving averages (MDA8) were calculated based on hourly $\mathrm{O}_{3}$ monitoring data at 15 monitoring stations across the PRD from 2007 to 2018. Missing data were imputed based on yearly, monthly, weekly, and hourly averages or were replaced by the $\mathrm{O}_{3}$ data from the nearest monitoring station [36]. Data for 4285 days at the 15 stations were included and the geographical distribution of the data is shown in Figure 1. The latitudes/longitudes and the types of functional areas where the stations are located are shown in Table 1. Meteorological data during the same period, including daily maximum 2-m temperature $\left(\mathrm{T},{ }^{\circ} \mathrm{C}\right)$, daily minimum relative humidity $(\mathrm{RH}, \%)$, total net surface solar radiation $\left(\mathrm{SSR}, \mathrm{J} / \mathrm{m}^{2}\right)$, and $10-\mathrm{m}$ mean wind speeds ( $\mathrm{u}$ and $\mathrm{v}, \mathrm{m} / \mathrm{s}$; the absolute values of $\mathrm{u}$ and $\mathrm{v}$ indicate wind speeds, with positive and negative $\mathrm{u}$ and $\mathrm{v}$ values indicating westerly/southerly and easterly/northerly wind directions, respectively) were retrieved from the European Center for Medium-range Weather Forecast (ECMWF) simulations. Spatial and temporal resolutions were $0.125^{\circ} \times 0.125^{\circ}$ and $3 \mathrm{~h}$, respectively. The meteorological conditions at each $\mathrm{O}_{3}$ monitoring station are represented by the simulation data at the point closest to the station, as indicated by the red stars in Figure 1.

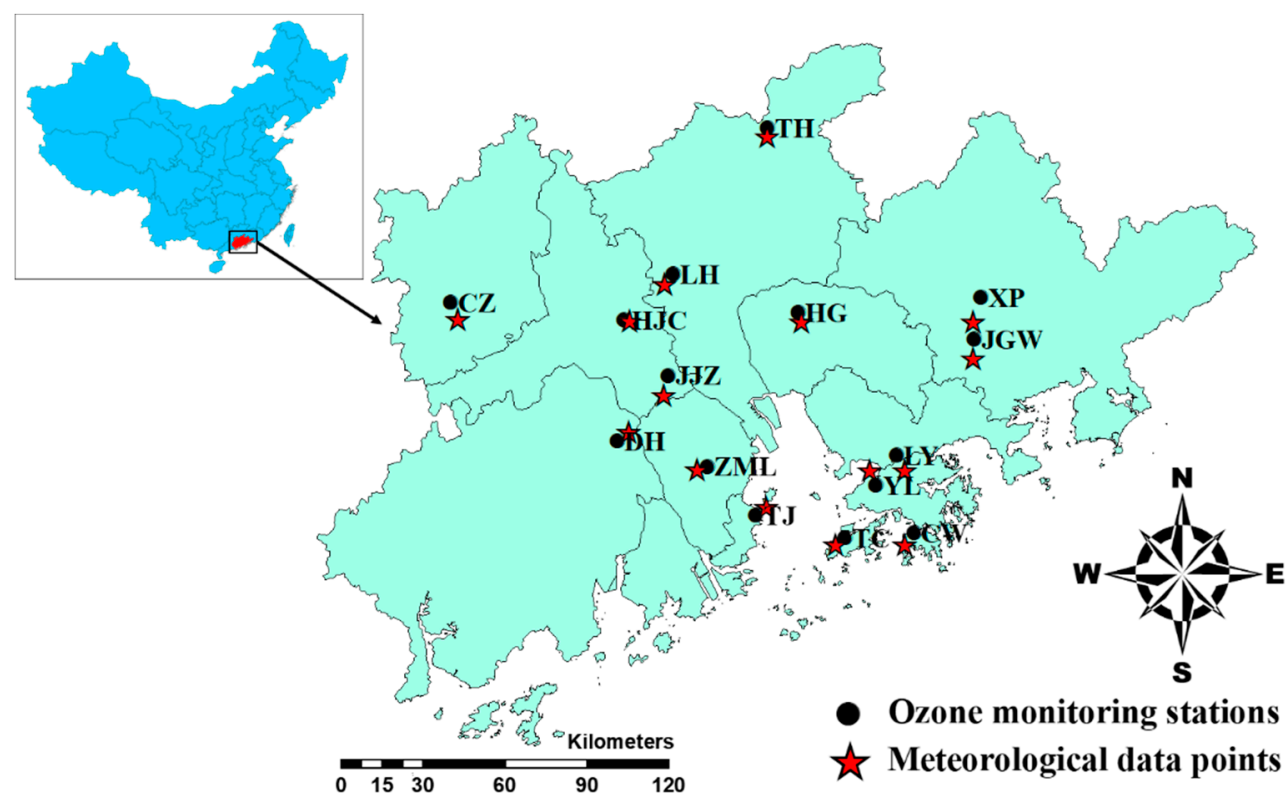

Figure 1. Distribution of $\mathrm{O}_{3}$ monitoring stations and meteorological data points in the Pearl River Delta.

\subsection{Identification of the Impacts from Local, Non-Local and Meteorological Factors on $\mathrm{O}_{3}$}

To better understand the correlations between $\mathrm{O}_{3}$ and meteorological variables, time $(t)$ data series $X(t)$ were separated into short-term (ST), seasonal (SE), and long-term (LT) components as expressed in Equation (1) [37,38].

$$
X(t)=L T(t)+S E(t)+S T(t)
$$


The sum of seasonal and long-term trend components is the baseline, and each component can be determined using a $K Z$ filter, which repeats the iterations of a moving average to remove the high-pass signal defined by:

$$
Y_{i}=\frac{1}{m} \sum_{j=-k}^{k} A_{i+j}
$$

where $k$ is the number of values included on each side, the window length $m=2 k+1, i$ is the interval time, $j$ is the window variables, and $Y$ is the output time series. Different time scales can be obtained by changing the window length and the number of iterations $[39,40]$. A KZ $(15,5)$ filter with a window length of 15 with five iterations removes cycles of 33 days referring to the baseline variations $(B L)$.

$$
B L(t)=K Z_{(15,5)}=L T(t)+S E(t)=K Z_{(365,3)}+S E(t)
$$

The long-term trend can be separated from the raw data by $K Z(365,3)$ with a period $>632$ days, and then the seasonal and short-term component $S T(t)$ can be derived by

$$
\begin{gathered}
S E(t)=K Z_{(15,5)}-K Z_{(365,3)} \\
S T(t)=X(t)-B L(t)=X(t)-K Z_{(15,5)}
\end{gathered}
$$

To explore the factors driving the temporal evolution of $\mathrm{O}_{3}$ aggregation and the impacts of meteorological conditions, local and non-local contributions were identified. The methods were as described in our related studies [28]. Briefly, a multiple linear regression (MLP) model was used to perform meteorological adjustments. Local and nonlocal sources were identified with an empirical orthogonal function (EOF) model and their contributions were estimated with absolute principal component scores (APCS). In our previous investigations, we treated the first principal as non-local, and local contributions were determined by subtracting non-local values from the original data. The statistic models were developed with $R$ language (version 3.5).

Table 1. Location of fifteen $\mathrm{O}_{3}$ monitoring stations across the Pearl River Delta and their environmental background.

\begin{tabular}{cccccc}
\hline Station & Full Name & City & Longitude (E) & Latitude (N) & Environmental Background \\
\hline CW & Central/Western & Hong Kong & 114.15 & 22.28 & Residential/Commercial \\
CZ & Chengzhong & Zhaoqing & 112.47 & 23.05 & Residential/Commercial \\
DH & Donghu & Jiangmen & 113.08 & 22.59 & Urban \\
HG & Haogang & Dongguan & 113.73 & 23.03 & Residential/Commercial \\
HJC & Huijingcheng & Foshan & 113.10 & 23.00 & Residential/Commercial \\
JGW & Jinguowan & Huizhou & 114.38 & 22.93 & Residential \\
JZ & Jinjuzui & Foshan & 113.26 & 22.81 & Suburban \\
LH & Luhu & Guangzhou & 113.28 & 23.15 & Urban \\
LY & Liyuan & Shenzhen & 114.09 & 22.55 & Urban \\
TC & Tung Chung & Hong Kong & 113.91 & 22.27 & Residential \\
TH & Tianhu & Guangzhou & 113.62 & 23.65 & Rural \\
TJ & Tangiia & Zhuhai & 113.58 & 22.34 & Commercial/Industrial \\
XP & Xiapu & Huizhou & 114.40 & 23.07 & Commercial \\
YL & Yuen Long & Hong Kong & 114.02 & 22.44 & Residential \\
ZML & Zimaling & Zhongshan & 113.40 & 22.50 & Residential/Commercial \\
\hline
\end{tabular}

\subsection{Determination of Relationships between $\mathrm{O}_{3}$ and Meteorological Factors}

MLP was conducted using stepwise regression between baseline $\mathrm{O}_{3}$ values and meteorological factors in determining the coefficients of determination [41,42]. We ignored the 
short-term component as it was weakly correlated compared with the relations between baseline $\mathrm{O}_{3}$ and meteorological variables [35].

$$
A_{B L}(t)=a_{B L}+\sum b_{B L i} \cdot M_{B L i}+\epsilon_{B L}(t)
$$

where $A_{B L}(t)$ and $M_{B L}$ are the baselines of the $\mathrm{O}_{3}$ and meteorological factors, respectively. The parameters $a, b$, and $\in$ are fitted parameters and the residual term. The coefficient of determination $\left(\mathrm{R}^{2}\right)$ of MLP reflects the relation between $\mathrm{O}_{3}$ and meteorological conditions, and $\mathrm{R}^{2}$ values between $\mathrm{O}_{3}$ and single meteorological factors were obtained if $M_{B L i}$ in Equation (6) contains one meteorological factor. The negative sign will be added to $\mathrm{R}^{2}$ if there exists a negative correlation between $\mathrm{O}_{3}$ and the single meteorological factor.

\subsection{Calculation of Degree of Aggregation Dispersion of Stations with Similar $\mathrm{O}_{3}$ Levels}

The global Moran's I index (GM) can be used as a spatial autocorrelation analysis technology to explore the dispersion or unification of attribute values in a given region. In this case, it reflects the correlations of $\mathrm{O}_{3}$ concentrations at different stations, taking the spatial weights of all stations into account. GM values range from -1 to 1 , with positive/negative values indicating positive/negative correlations among all $\mathrm{O}_{3}$ stations. $\mathrm{GM}$ values approaching 1 or -1 represent strong positive or negative relations, respectively, and a GM value approaching 0 indicates no obvious association. GM was calculated as follows.

$$
\begin{gathered}
\mathrm{I}=\frac{\sum_{i=1}^{n} \sum_{j=i}^{n} w_{i j}\left(x_{i}-\bar{x}\right)\left(x_{j}-\bar{x}\right)}{S \sum_{i=1}^{n} \sum_{j=i}^{n} w_{i j}} \\
\mathrm{~S}=\frac{1}{n} \sum\left(x_{i}-\bar{x}\right)^{2} \\
\bar{x}=\frac{1}{n} \sum_{i=1}^{n} x_{i}
\end{gathered}
$$

where $I$ is GM, $x_{j}$ is the observed value of a region, $w_{i j}$ is the spatial weight matrix, and $S$ is variance. We utilized local Moran'I (LM) to explore the correlation of a station with its adjacent stations in a small area. LM constitutes the normalized $\mathrm{O}_{3}$ concentration of a station and the adjacent station and their scatter plots in quadrant can discern their correlations. It exposes the heterogeneity shadowed by GM and is often involved in recognizing pollution hotspots in geography [43-45]. Three stations closest to a site were used to calculate the normalized lagged $\mathrm{O}_{3}$ concentration, which represents the average $\mathrm{O}_{3}$ level adjacent to a site. The normalized $\mathrm{O}_{3}$ value of a site and its lagged value were assigned to a two-dimensional plot and correlations between the two were visualized according to their locations in quadrants (Figure 2). "high-high" (H-H) in the first quadrant [(1) in Figure 2] indicates a site with a high attribute that is encircled by high-attribute sites. Low-high (L-H) in the second quadrant, low-low (L-L) in the third quadrant, and high-low $(\mathrm{H}-\mathrm{L})$ in the fourth quadrant indicate a low-attribute site encircled by high-attribute sites, a low-attribute site encircled by low-attribute sites, and a high-attribute site encircled by low-attribute sites, respectively. GM values varied from -1 to +1 , with values closer to 1 indicating more strongly positive correlations, which are deemed $\mathrm{H}-\mathrm{H}$ or L-L patterns, values closer to -1 indicating negative correlations among stations, which are deemed H-L or L-H patterns, and values closer to 0 indicating weaker correlations among stations. 


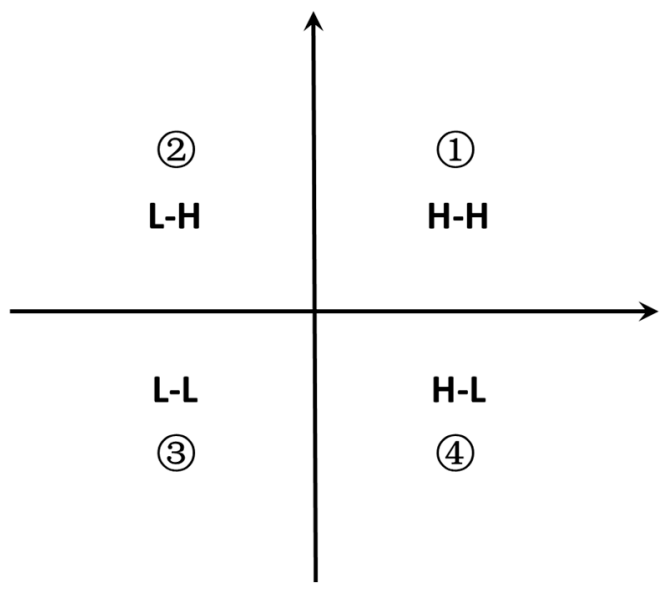

Figure 2. Scatter plots of local Moran'I in quadrants and the significance of correlation of a station with adjacent stations.

\section{Results}

\subsection{Aggregation of Stations with Similar $\mathrm{O}_{3}$ Concentrations over Different Time Scales}

$\mathrm{O}_{3}$ is a regional pollution issue with stations showing similar concentrations distributed close together. The concentration is always affected by meteorological conditions, local precursor emissions and transport of non-local $\mathrm{O}_{3}$ or precursors from outside the local area. The heterogeneity or consistency of average $\mathrm{O}_{3}$ concentrations at multiple stations may vary with changes in these factors, causing fluctuations in the correlations between each station and its adjacent stations. In this section, the aggregation on different time scales, long-term evolution, and driving factors are analyzed to explore the pollution characteristics.

\subsubsection{Global Moran's I on Different Time Scales}

GM variations in annual average $\mathrm{O}_{3}$ concentrations are shown in Figure 3 (black line). The values range from a minimum of 0.25 in 2008 to a maximum of 0.59 in $2012(p<0.05$ except 2018). The positive GM values indicate that stations with similar $\mathrm{O}_{3}$ concentrations distributed agminated in the PRD. The sharp increase from 2007 to 2012 implies that $\mathrm{O}_{3}$ concentrations converged on similar levels during this period and the almost constant GM during the period 2013 to 2017 indicates that the overall spatial distribution of annual average $\mathrm{O}_{3}$ values remained stable throughout the area.

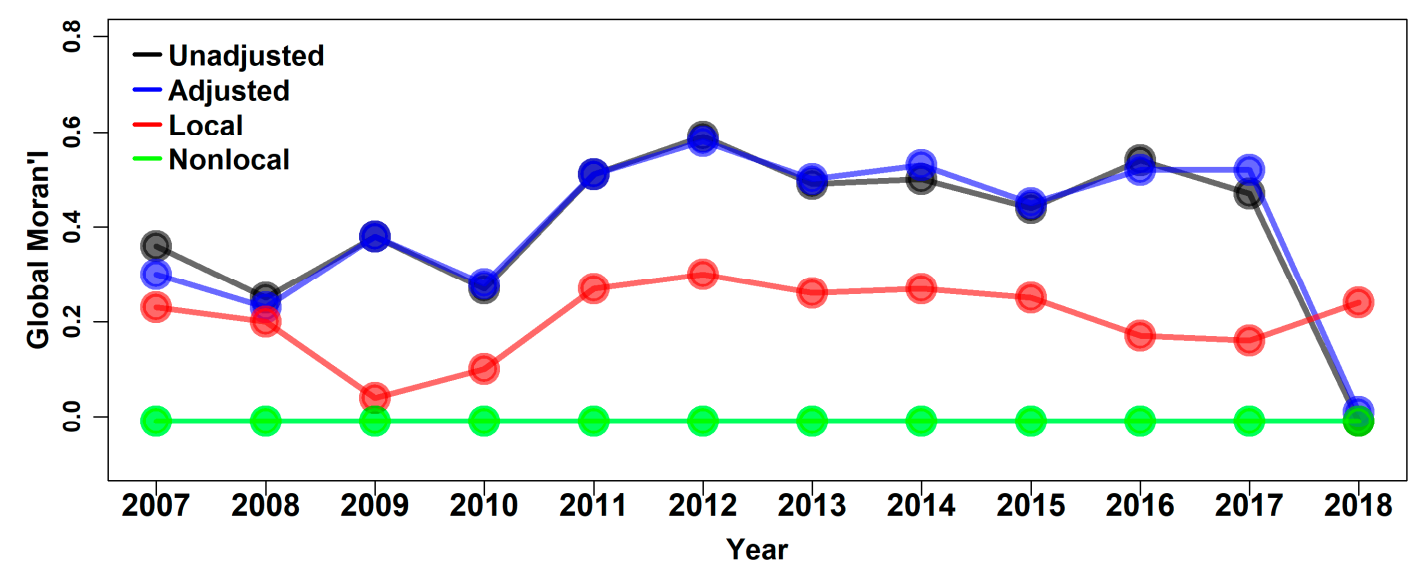

Figure 3. Annual Global Moran'I of different components from 2007 to 2018 in PRD. Lines in black, blue, red, and green are the original, meteorologically adjusted, local and nonlocal data, respectively. 
To clarify the factors that drive annual GM values, the impacts of meteorological conditions and local and non-local contributions were identified and their annual GM values are shown in Figure 3. We found that GM values were almost constant regardless of fluctuations in meteorological conditions. This implies that the annual average spatial distribution of $\mathrm{O}_{3}$ is independent of fluctuations in meteorological conditions. Our previous investigation demonstrated that $\mathrm{O}_{3}$ concentrations were sensitive to meteorological conditions in the western region of the PRD [28], while $\mathrm{O}_{3}$ concentrations were high in the northeastern region during the period 2013 to 2017 [46]. Meteorological conditions still have an important influence on $\mathrm{O}_{3}$ concentrations, and we discuss the spatiotemporal evolution of the correlation between $\mathrm{O}_{3}$ and meteorological conditions in Section 3.2.

The annual GM (red line, local GM) decreased when non-local contributions were removed and the annul non-local GM retained the same negative values. Therefore, we inferred that the overall temporal GM was likely driven by local contributions as local and annual GM showed similar temporal variations. Negative non-local GM values near 0 imply that $\mathrm{O}_{3}$ transported from outside of the area was distributed discretely in the PRD. GM values would be increased by the impact of non-local contributions as the discrepancies between $\mathrm{O}_{3}$ concentrations at different stations were evened out by non-local contributions. These observations emphasize that $\mathrm{O}_{3}$ pollution is a regional issue and was intensified by local contributions from 2007 to 2012. Furthermore, $\mathrm{O}_{3}$ concentrations at most stations in the PRD increased during this period [28], and the increasing GM values imply that $\mathrm{O}_{3}$ levels increased faster at stations with previously low levels, thereby reducing the difference compared to high $\mathrm{O}_{3}$ stations. Non-local contributions had no effect on temporal GM fluctuations, whereas they enhanced $\mathrm{O}_{3}$ concentrations at low-level stations. Therefore, local and regional cooperation is necessary to restrict $\mathrm{O}_{3}$ pollution.

It should be noted that GM dropped to $0.1(p>0.05)$ in 2018, implying that $\mathrm{O}_{3}$ concentrations were discretely distributed, which may have been related to abnormal weather in that year. Fluctuations in T and SSR intensified, accompanied by significant differences in temperature and precipitation compared to previous years, and there were several typhoons in 2018 [47]. Different stations were affected to varying degrees by meteorological conditions, resulting stations in high/low $\mathrm{O}_{3}$ levels encompassed by low/high levels stations, which should be explored further in future studies.

Analysis of the monthly GM values for each year compared with the averages of all years (Figure 4) revealed that months with high $\mathrm{O}_{3}$ levels (marked with digits) were usually coupled with high GM values, indicating that $\mathrm{O}_{3}$ concentrations at most stations throughout the region became more similar in $\mathrm{O}_{3}$ seasons. $\mathrm{GM}$ values were low or even negative in months with low $\mathrm{O}_{3}$ concentrations. The polarization of $\mathrm{GM}$ values in different months demonstrates that control of $\mathrm{O}_{3}$ during periods of high pollution requires the cooperation of the whole area, and appropriate measures should be applied to stations with relatively high $\mathrm{O}_{3}$ concentrations when concentrations are low during spring and winter.

\subsubsection{GM on Different Time Scales}

GM reflects the autocorrelation of the $\mathrm{O}_{3}$ concentrations of all stations using a single index. This index indicates only the degree of aggregation or dispersion of $\mathrm{O}_{3}$ concentrations in the region. However, heterogeneity between a single station and its adjacent regions within a small district will be shadowed by GM values. Hence, local autocorrelation analysis was performed to examine these features. As shown in Figure 5a, stations were distributed mainly in the first and third quadrants, indicating that stations were surrounded by other stations with similar $\mathrm{O}_{3}$ levels, consistent with high positive $\mathrm{GM}$ values. CW, TC, $\mathrm{TL}$, and LY with low concentration levels located in or near Hong Kong (HK) are associated with the L-L pattern because of their relatively low precursor emissions [19]. Furthermore, dilution by the sea breeze and increased precipitation in coastal regions would also lead to low $\mathrm{O}_{3}$ levels in these areas. The remaining stations mostly fell within the first quadrant, indicating that these stations simultaneously experienced high $\mathrm{O}_{3}$ levels compared with those of sites in or near $\mathrm{HK} \mathrm{O}_{3}$ values were highest at $\mathrm{TH}$, and the three nearest stations, 
HG, HJC, and LH, had similarly high values. These sites are located in the north of the PRD and in northerly winds are the most susceptible to non-local $\mathrm{O}_{3}$ from inland. With a southerly wind, $\mathrm{O}_{3}$ from the south will settle in areas to the north. Both situations could facilitate the accumulation of $\mathrm{O}_{3}$ in areas north of the PRD. JGW and TJ were distributed in the fourth quadrant because of the influence of nearby $\mathrm{HK}$, which had the lowest $\mathrm{O}_{3}$ concentrations. Therefore, programs to restrain $\mathrm{O}_{3}$ in the PRD should take into account geographical location and the effects on upwind areas.

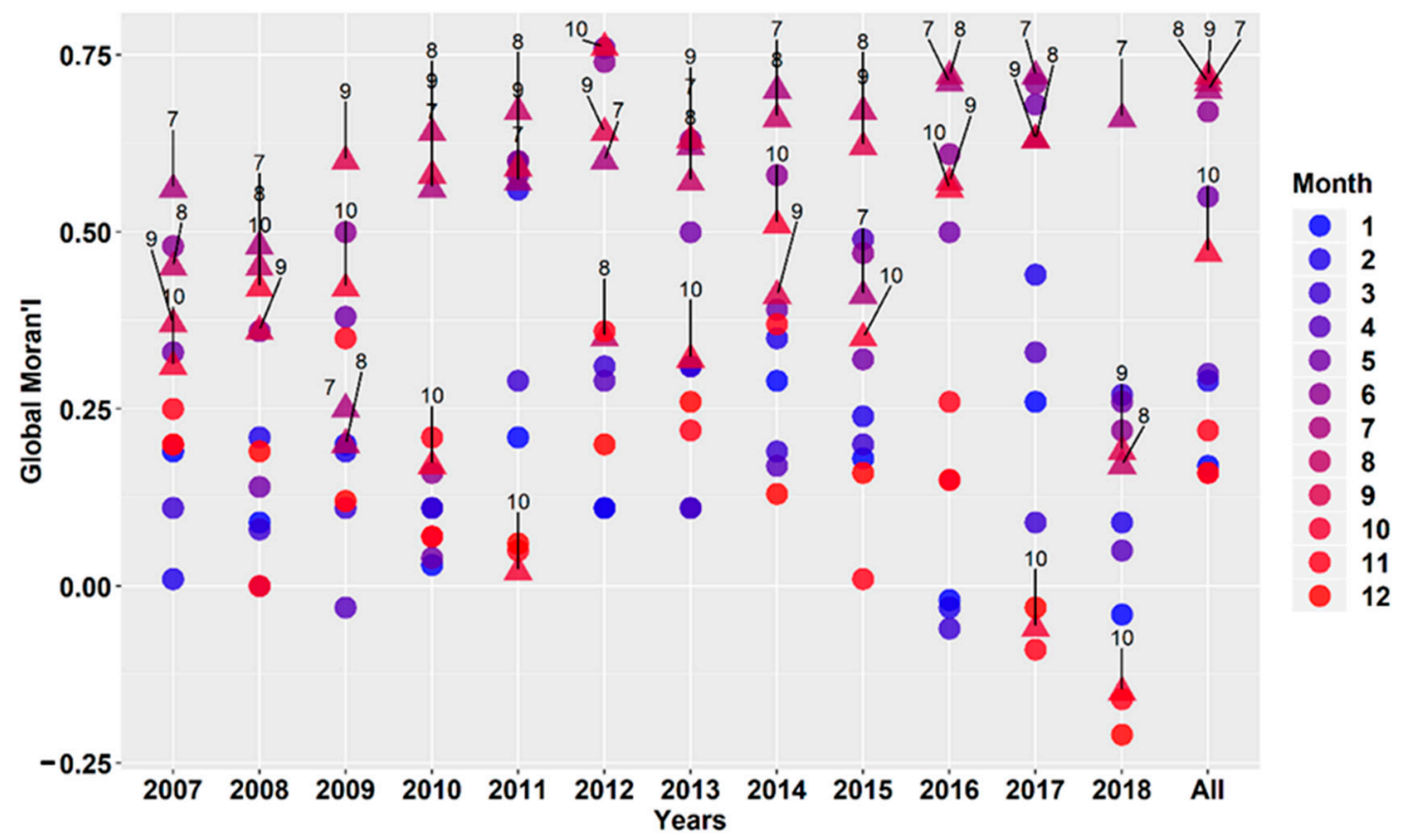

Figure 4. Monthly Global Moran'I variations from 2007 to 2018 in PRD. Colorful solid dots indicate different months in each year and digits hanging above the solid dots mark the high $\mathrm{O}_{3}$ concentration months (7-10). "All" is $\mathrm{O}_{3}$ average throughout all the years.

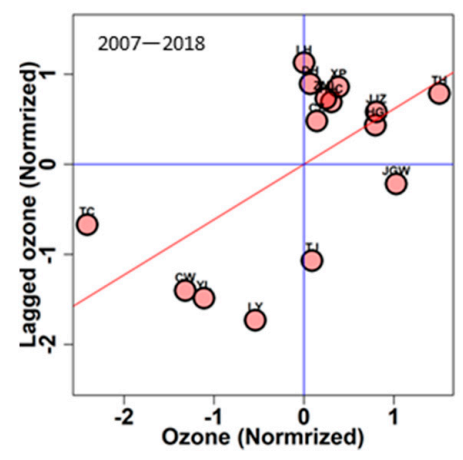

(a) Local Moran'I scatter diagram of the average $\mathrm{O}_{3}$ throughout 2007 to 2018.

Figure 5. Cont. 

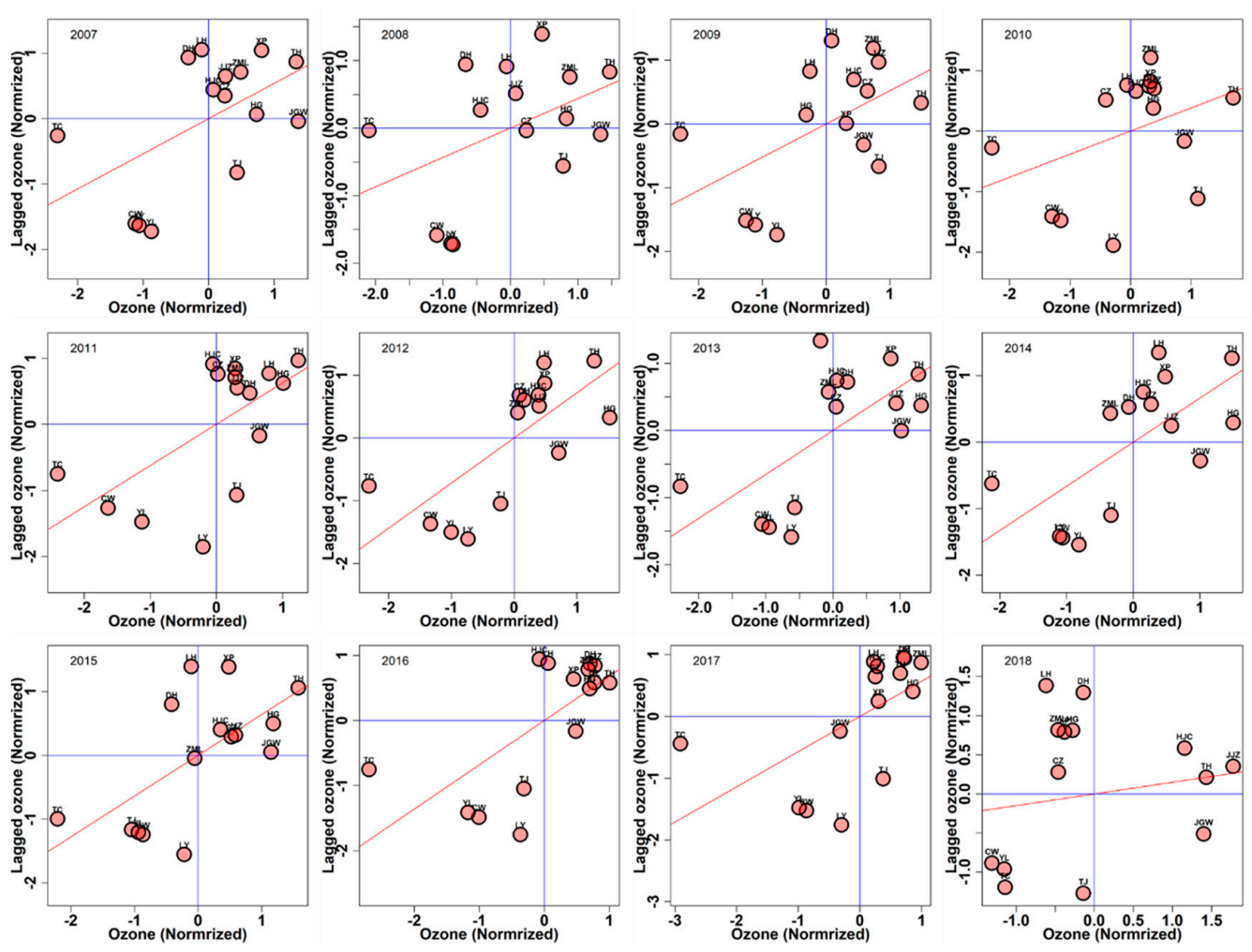

(b) Local Moran'I scatter diagram of the annual average $\mathrm{O}_{3}$ from 2007 to 2018.
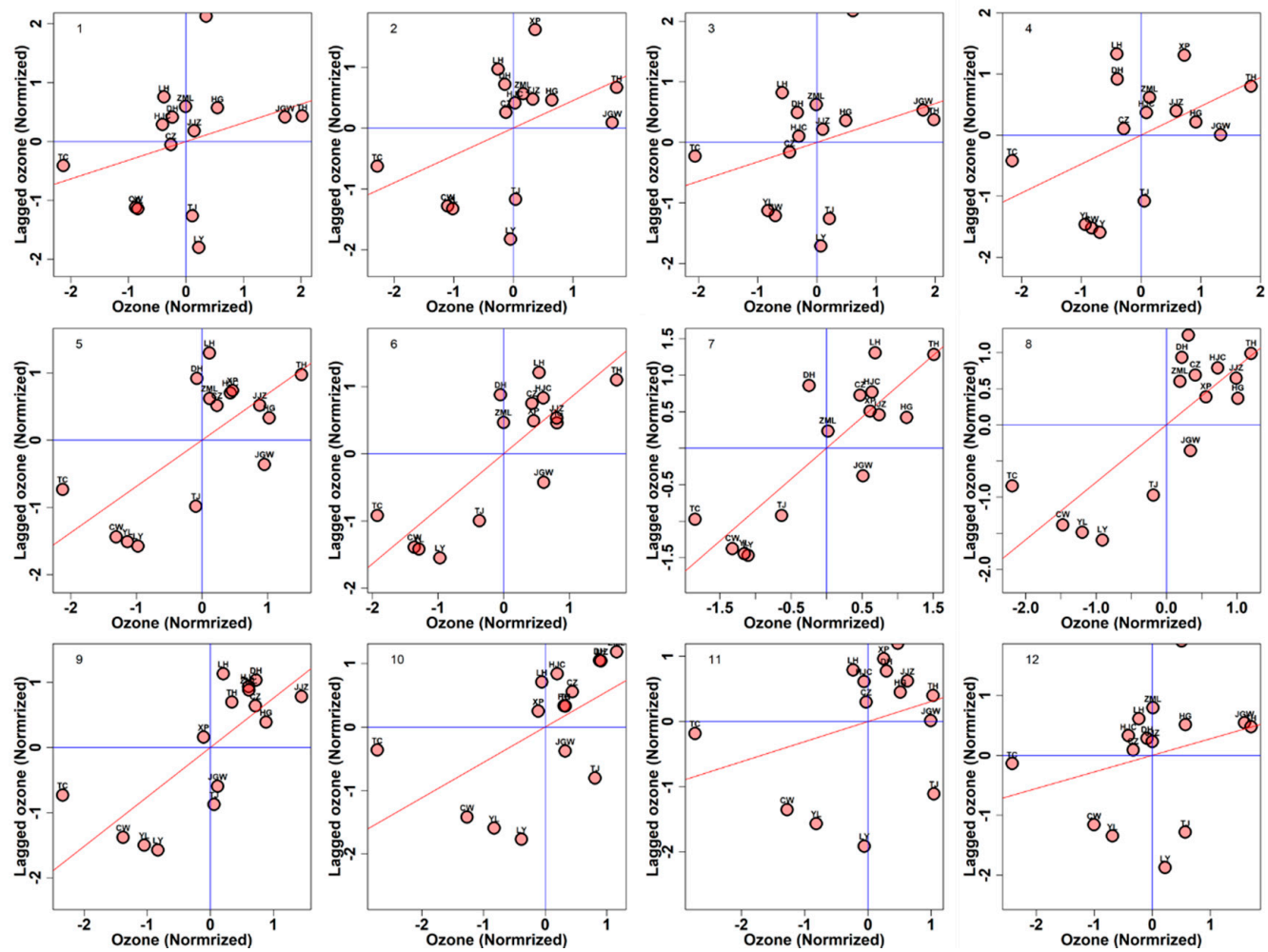

(c) Local Moran'I scatter diagram of the monthly average $\mathrm{O}_{3}$

Figure 5. Local Moran'I variations in different time scales $(\mathbf{a}-\mathbf{c})$ in PRD. $a, b$ and c are local Moran'I of the averages through 2007 to 2018, each year and each month respectively. The horizontal and vertical pink lines specified the 0 location of $x$ and $y$ axises and the $y$ Indicates the normalized ozone concentration. 
Variations in the scatter diagram of LM for the different years are shown in Figure 5b. Hong Kong remained L-L and most other regions stabilized in the first quadrant throughout the investigation. However, although some stations, such as LH and DH, switched among different quadrants, they finally settled in the first or second quadrant, indicating that these stations coexisted with surrounding high $\mathrm{O}_{3}$ regions. The pattern of GM values in 2018 differed significantly from previous years, which is consistent with the low GM values shown in Figure 3. $\mathrm{O}_{3}$ concentrations at $\mathrm{TH}, \mathrm{HJC}$, and JJZ were still relatively high and these stations remained in the first quadrant, while $\mathrm{O}_{3}$ concentrations in other regions were relatively low and switched to the second quadrant. These observations may have been related to abnormal meteorological events in 2018 and require further investigation.

To explore the monthly aggregation in local areas as part of the whole region, we calculated the lagged $\mathrm{O}_{3}$ levels of all stations with the monthly averages from all periods and the results are shown in Figure 5c. The stations were allocated to the quadrants from January to April and during December. This was consistent with the monthly GM values, which were low during the same periods (Figure 4). High $\mathrm{O}_{3}$ concentrations occurred from May to November in the PRD with high monthly GM values (Figure 4) and with monthly local autocorrelations having $\mathrm{H}-\mathrm{H}$ and L-L patterns (Figure 5c). These observations show that the discrepancies of $\mathrm{O}_{3}$ concentration from the whole region were shrank in high $\mathrm{O}_{3}$ level months, which implied high/low $\mathrm{O}_{3}$ stations were enclosed with high/low stations around during high pollution periods. Inversely, high/low $\mathrm{O}_{3}$ stations were encircled by low/high stations around during non-high pollution periods relatively. These observations indicate the need to formulate different $\mathrm{O}_{3}$ control measures according to specific local pollution conditions.

\subsection{Spatial Distribution of Meteorological Conditions- $\mathrm{O}_{3}$ Correlations and Its Temporal Evolutionary Characteristics}

The results outlined in Section 2 indicate that annual GM values were independent of meteorological conditions. However, $\mathrm{O}_{3}$ concentrations have been shown to be markedly influenced by meteorological fluctuations [29,48-52]. This section discusses the correlation between meteorological fluctuations and their spatiotemporal evolution. As shown in Figure 6a, the $\mathrm{R}^{2}$ values between $\mathrm{O}_{3}$ values and all of the selected meteorological variables (MET) were high throughout the period 2007 to 2018 in southwestern regions and low in northeastern regions, with maximum values of $0.74,0.72$, and 0.67 at $\mathrm{YL}, \mathrm{CZ}$, and $\mathrm{ZML}$, respectively. Such high correlations indicate the consistency of variations in $\mathrm{O}_{3}$ concentrations and meteorological conditions and the southwestern region is likely sensitive to meteorological conditions [32-34]. $\mathrm{R}^{2}$ values in the northeastern region were relatively low, with a minimum value of 0.24 at $\mathrm{TH}$ (Figure 6a), indicating that $\mathrm{O}_{3}$ in these areas was likely regulated mainly by changes in its precursors or by non-local transportation.

$\mathrm{R}^{2}$ values between $\mathrm{O}_{3}$ and single meteorological variables are shown in Figure $6 \mathrm{~b}-\mathrm{f}$. The $\mathrm{R}^{2}$ of SSR and T (b and c) had similar spatial distributions and governed the overall picture of MET $\mathrm{R}^{2}$, implying that they were the major factors influencing $\mathrm{O}_{3}$ concentrations. $\mathrm{R}^{2}$ values were low in coastal regions, but high in western and central-western areas. This was because precursor emissions of $\mathrm{O}_{3}$ were concentrated in the western and centralwestern areas [36], and temperature and solar radiation can influence $\mathrm{O}_{3}$ production directly or indirectly. Areas with high precursor emissions are more sensitive to T and SSR and will probably experience higher $\mathrm{O}_{3}$ levels as T and SSR will increase with climate change and with the alleviation of particulate matter pollution. RH showed slight negative correlations in most areas, especially in coastal cities (Figure 6d), which was likely associated with wet deposition of $\mathrm{O}_{3}$ precursors. The $\mathrm{R}^{2}$ values of $\mathrm{u}$ and $\mathrm{v}$ (Figure $6 \mathrm{e}-\mathrm{f}$ ) had similar spatial distributions and magnitudes, and the negative correlations near the ocean were probably associated with dilution by sea breeze. We speculate that the positive $\mathrm{R}^{2}$ values in the north reflect transport of $\mathrm{O}_{3}$ and its precursors from inland. 

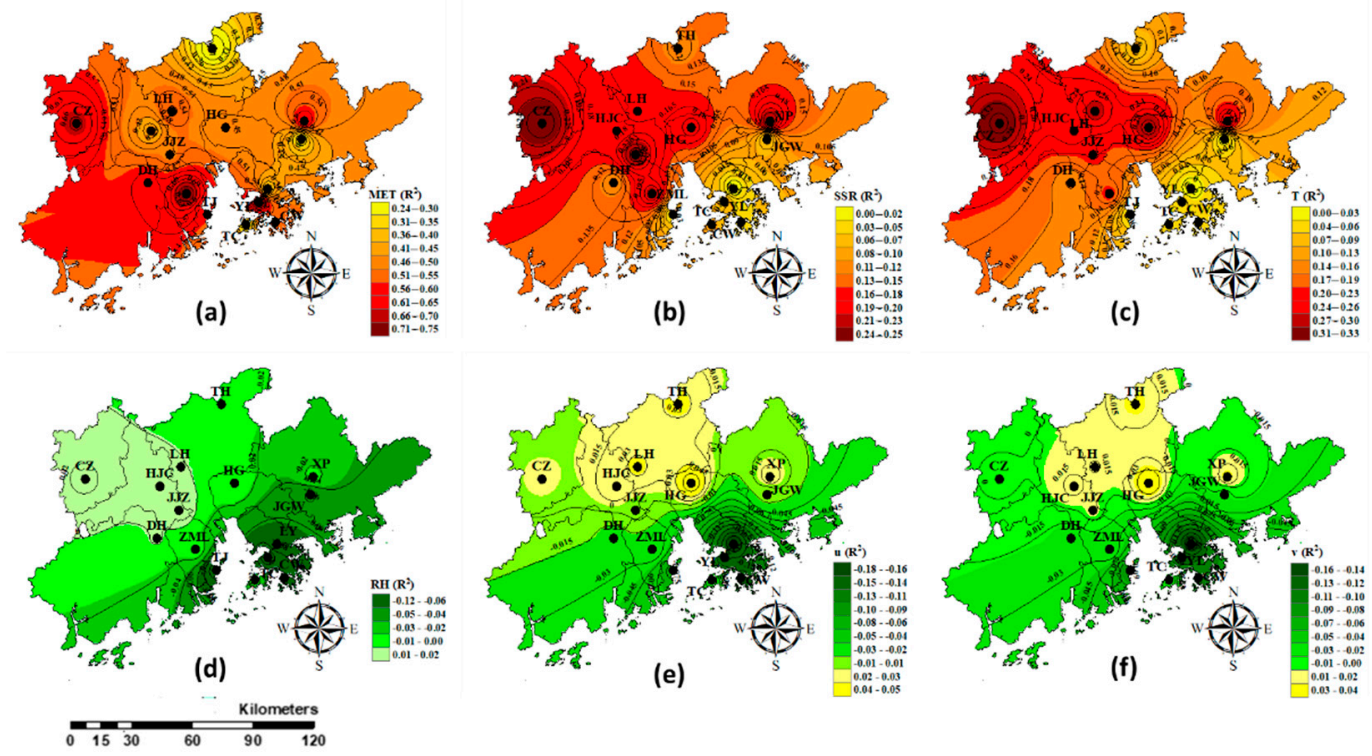

Figure 6. Coefficients of determination $\left(\mathrm{R}^{2}\right)$ between the baseline of Maximum daily 8-h moving averages (MDA8) and baselines of meteorological variables from 2007 to 2018 (a-f) is $\mathrm{R}^{2}$ between $\mathrm{O}_{3}$ and all the five meteorological factors (MET), total net surface solar radiation (SSR, c), daily maximum 2-m temperature $(\mathrm{T}, \mathbf{b})$, daily minimum relative humidity (RH, $\mathbf{d})$, 10-m mean wind ( $u$, e and $v, \mathbf{f}$ ) respectively).

The annual geographical distributions and average annual variations in $\mathrm{R}^{2}$ between $\mathrm{O}_{3}$ and all meteorological factors are shown in Figures 7 and 8. High correlations were seen in the southwest in most years, but there were large discrepancies between different years (Figure 7). In the long term, the variations in $\mathrm{R}^{2}$ showed no obvious tendencies for the whole region, except that $R^{2}$ was relatively low from 2016 to 2018. Examination of the spatial distribution of $\mathrm{R}^{2}$ for each meteorological variable with $\mathrm{O}_{3}$ (Figures S1-S5) implied that the sensitivity of the western area to meteorological conditions was due mainly to SSR and $\mathrm{T}$ and that $\mathrm{u}$ and $\mathrm{v}$ were responsible for the totally high $\mathrm{R}^{2}$ values in the northeast from 2015. $R^{2}$ values in SSR and T had similar spatial distributions throughout all periods and were higher during the last 8 years than the first few years. Negative correlations were seen between $\mathrm{O}_{3}$ and $\mathrm{RH}$ in most periods, especially in coastal areas. The $\mathrm{R}^{2}$ values of $\mathrm{u}$ and $\mathrm{v}$ with $\mathrm{O}_{3}$ were positive in the north and became more intense with the years, signifying that ozone was more sensitive to wind in the north, while values were negative in the south and the last to become positive, signifying that $\mathrm{O}_{3}$ in the south was likely induced by wind.

Annual MET $\mathrm{R}^{2}$ (black dashed line in Figure 8) values showed a slight decrease from 2007 to 2018, accompanied by increases in $\mathrm{R}^{2}$ values for SSR and T and reductions in RH, $\mathrm{u}$, and $\mathrm{v}$. Hence, MET $\mathrm{R}^{2}$ was suppressed by $\mathrm{RH}, \mathrm{u}$, and $\mathrm{v}$ overall. $\mathrm{R}^{2}$ values for SSR and $\mathrm{T}$ remained highly consistent in tendency and magnitude due to the high correlation between SSR and T. The decline in $\mathrm{NO}_{\mathrm{x}}$ and increase in VOCs were relatively steady over the last decade [1], so the peaks in 2012 and 2016 were probably related to the marked fluctuations in SSR and T (Figure S6). The increases in $\mathrm{R}^{2}$ values for $\mathrm{T}$ and SSR imply that the PRD, especially the areas with $\mathrm{O}_{3}$ concentration sensitive to meteorological conditions, will likely suffer more severe $\mathrm{O}_{3}$ pollution in the future at present emission levels. On the whole, $u, v$, and RH acted as diluters initially based on the negative $R^{2}$, and this occurred mainly in the southern parts of the PRD; $\mathrm{O}_{3}$ showed positive correlations with $\mathrm{u}$ and $\mathrm{v}$, and was independent of $\mathrm{RH}$ in the last few years. Xue et al. reported that Hong Kong was experiencing increasing $\mathrm{O}_{3}$ transport from the PRD [53]. Therefore, we assume that the negative correlations of $u-R^{2}$ and $v-R^{2}$ values occurred when dilution by wind was dominant, and $\mathrm{O}_{3}$ concentrations in the PRD were relatively low. More $\mathrm{O}_{3}$ was transported to the south from the PRD when $\mathrm{O}_{3}$ levels in the PRD were high, leading to positive $u$ and $v R^{2}$ values in the southern regions of the PRD. These findings imply that efforts to 
reduce emissions may be offset by adverse meteorological conditions and indicate that it is necessary to clarify $\mathrm{O}_{3}$ transport by the wind to restrict levels in the PRD.
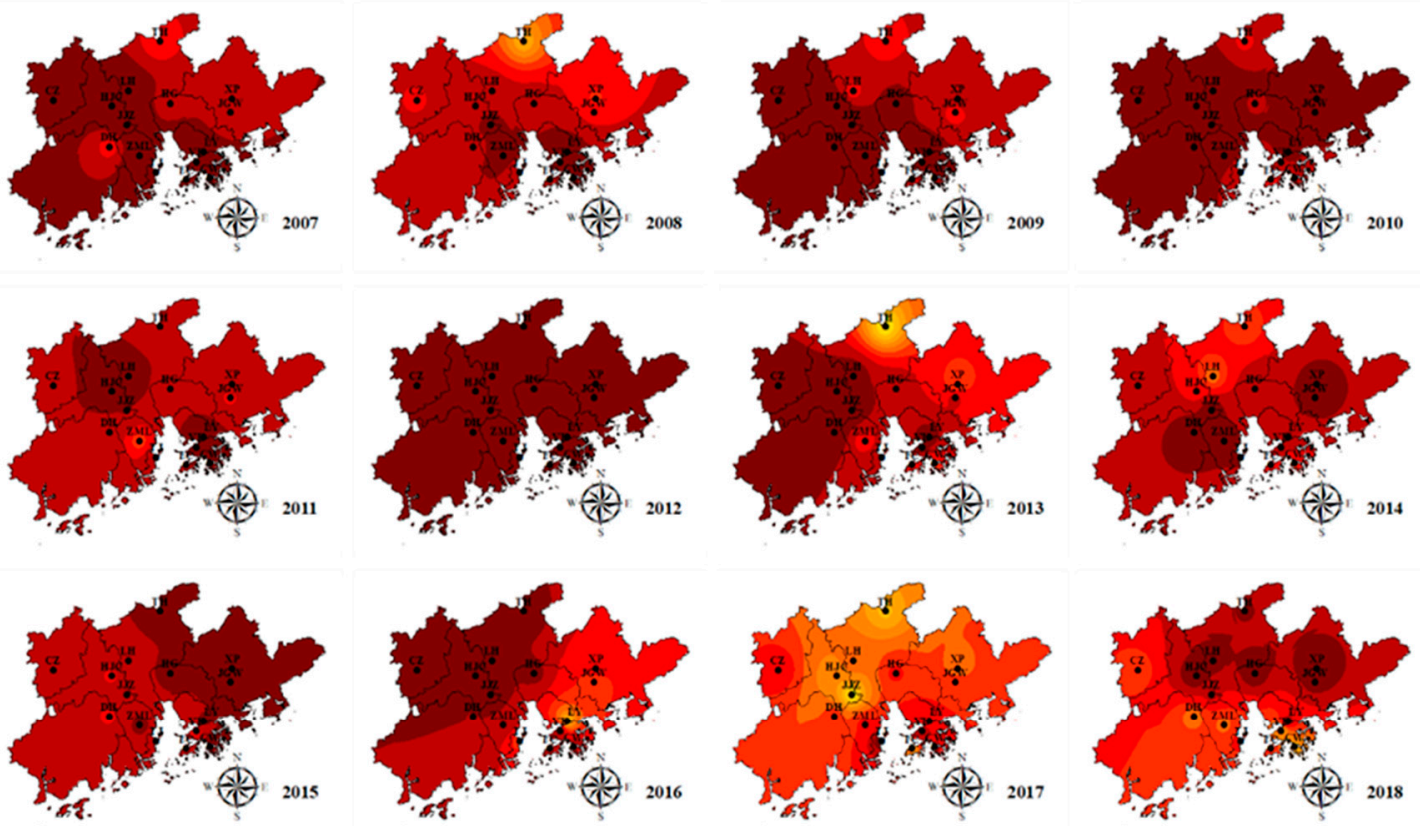

\section{$\operatorname{MET}\left(\mathbf{R}^{2}\right)$}

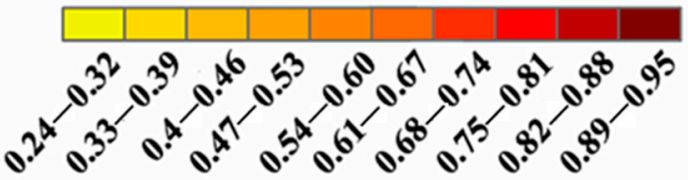

\begin{tabular}{llll}
0 & Kinometers \\
\hline 3060 & 120 & 180 & 240
\end{tabular}

Figure 7. Interannual temporal and spatial variations of coefficients of determination $\left(\mathrm{R}^{2}\right)$ between the baseline of MDA8 and baselines of all meteorological variables (SSR, T, RH, u and v) from 2007 to 2018.

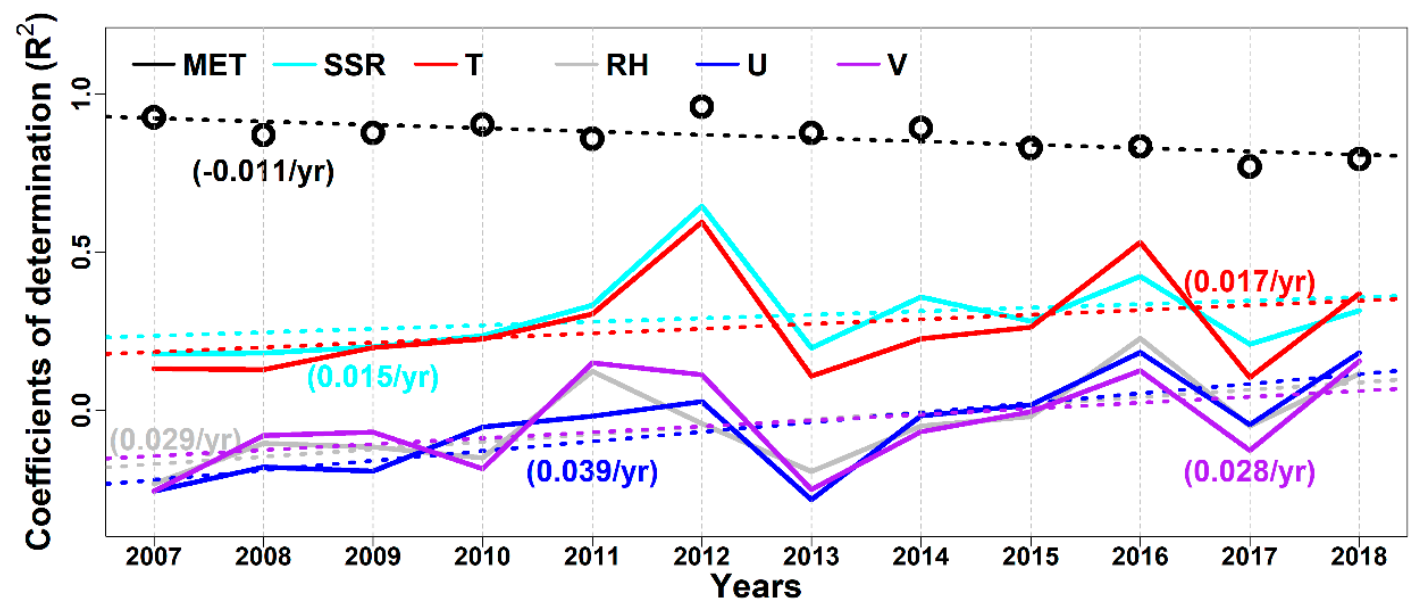

Figure 8. Coefficients of determination $\left(\mathrm{R}^{2}\right)$ between the baseline of daily MDA8 and baselines of meteorological variables from 2007 to 2018 (MET is $\mathrm{R}^{2}$ between $\mathrm{O}_{3}$ and all the five meteorological factors). Annotations in brackets indicate the increased rate of annual $\mathrm{R}^{2}$.

\section{Conclusions and Discussion}

In this study, the aggregation (as reflected by GM) of $\mathrm{O}_{3}$ concentrations at all stations in the PRD and their temporal evolution were analyzed to elucidate regional issues related to $\mathrm{O}_{3}$ pollution. The impacts of meteorology, local and non-local contribution were identified 
to determine the driving factors of GM variation. The results show that stations with similar $\mathrm{O}_{3}$ levels aggregated distributed more in PRD. The increases in annual GM from 2007 to 2012 indicate that the differences in $\mathrm{O}_{3}$ concentrations among stations decreased and $\mathrm{O}_{3}$ approached to a similar level. Further investigation showed that GM values were independent of meteorological conditions and were markedly enhanced by non-local contributions and that the temporal variations in GM were driven by local contributions. GM values were higher in $\mathrm{O}_{3}$ seasons and became small in low $\mathrm{O}_{3}$ months. Furthermore, stations near HK had similarly low levels and the remainder had high $\mathrm{O}_{3}$ levels, as characterized by $\mathrm{LM}$. Thus, regional $\mathrm{O}_{3}$ issues became more prominent, which was mainly due to local and non-local contributions.

To reduce $\mathrm{O}_{3}$ pollution in the $\mathrm{PRD}$, further substantial reductions in emissions are required. Cooperation between regions within the PRD and with environmental agencies outside the PRD will be crucial to reduce transport from upwind areas. Ozone concentration in the westerly of PRD was more sensitive to $\mathrm{T}$ and SSR, and the $\mathrm{R}^{2}$ between ozone and meteorological factors increased over the years, $\mathrm{so}_{3}$ concentrations will probably increase even if emissions are kept constant as the warming climate, and additional efforts are required to reduce pollution in these areas. Particularly, $\mathrm{RH}-\mathrm{R}^{2}$ values were negative in most areas and periods, which is reasonable due to wet deposition in $\mathrm{O}_{3}$ and its precursors. The $\mathrm{R}^{2}$ values of $\mathrm{u}$ and $\mathrm{v}$ were positive in northern regions and increased over the years, while being negative in southern regions and eventually becoming positive, implying that $\mathrm{O}_{3}$ was more likely to be transported into the area by wind, especially in the northern regions of the PRD. Therefore, it is necessary to characterize the impacts of meteorological conditions for effective emission reduction, and additional attention and efforts are needed in the meteorology-sensitive regions.

Supplementary Materials: The following are available online at https:/ /www.mdpi.com/2073-443 3/12/2/279/s1, Figure S1: Annual coefficients of determination $\left(R^{2}\right)$ between the baseline of daily MDA8 and SSR. Figure S2: Annual coefficients of determination $\left(R^{2}\right)$ between the baseline of daily MDA8 and T. Figure S3: Annual coefficients of determination $\left(R^{2}\right)$ between the baseline of daily MDA8 and RH. Figure S4: Annual coefficients of determination $\left(R^{2}\right)$ between the baseline of daily MDA8 and $u$. Figure S5: Annual coefficients of determination $\left(R^{2}\right)$ between the baseline of daily MDA8 and v. Figure S6: Annual variances of each meteorological variable.

Author Contributions: Conceptualization, L.Y. and Z.Y.; Data curation, Z.Y.; Formal analysis, L.Y., Z.Y., Z.H., H.W. and J.H.; Methodology, L.Y. and W.J.; Project administration, D.X.; Software, H.W.; Supervision, Z.Y.; Validation, Z.H., J.H. and L.L.; Visualization, L.Y.; Writing—original draft, L.Y.; Writing-review \& editing, Z.Y. All authors have read and agreed to the published version of the manuscript.

Funding: This work is supported by National Key Research and Development Project of China (No. 2018YFC1801602).

Institutional Review Board Statement: Not applicable.

Informed Consent Statement: Not applicable.

Data Availability Statement: The data sets are from Guangdong Environmental Monitoring Center and Hong Kong Environmental Protection Department in this study.

Acknowledgments: This work is supported by National Key Research and Development Project of China (No. 2018YFC1801602). The authors are grateful to Guangdong Environmental Monitoring Center and Hong Kong Environmental Protection Department for providing ozone monitoring data over the PRD for use in this study.

Conflicts of Interest: The authors declare that they have no known competing financial interests or personal relationships that could have appeared to influence the work reported in this paper. 


\section{References}

1. Bian, Y.; Huang, Z.; Ou, J.; Zhong, Z.; Xu, Y.; Zhang, Z.; Xiao, X.; Ye, X.; Wu, Y.; Yin, X. Evolution of anthropogenic air pollutant emissions in Guangdong Province, China, from 2006 to 2015. Atmos. Chem. Phys. 2019, 19, 11701-11719. [CrossRef]

2. Wang, Y.; Wang, H.; Guo, H.; Lyu, X.; Cheng, H.; Ling, Z.; Louie, P.; Simpson, I.; Meinardi, S.; Blake, D. Long-term O3-precursor relationships in Hong Kong: Field observation and model simulation. Atmos. Chem. Phys. 2017, 17, 10919-10935. [CrossRef]

3. Report on the State of Guangdong Provinccal Environment of 2019. Available online: http://gdee.gd.gov.cn/attachment/0/397/ 397371/3048134.pdf. (accessed on 17 February 2021).

4. Stevenson, D.S.; Young, P.J.; Naik, V.; Lamarque, J.; Shindell, D.; Voulgarakis, A.; Skeie, R.; Dalsoren, S.; Myhre, G.; Berntsen, T. Tropospheric ozone changes, radiative forcing and attribution to emissions in the Atmospheric Chemistry and Climate Model Intercomparison Project (ACCMIP). Atmos. Chem. Phys. Discuss. 2013, 13, 3063-3085. [CrossRef]

5. Thompson, A.; Balashov, N.; Witte, J.; Coetzee, J.; Thouret, V.; Posny, F. Tropospheric ozone increases over the southern Africa region: Bellwether for rapid growth in Southern Hemisphere pollution? Atmos. Chem. Phys. 2014, 14, 9855-9869. [CrossRef]

6. Mazzuca, G.; Ren, X.; Loughner, C.; Estes, M.; Crawford, J.; Pickering, K.; Weinheimer, A.; Dickerson, R. Ozone Production and Its Sensitivity to NOx and VOCs: Results from the DIS-COVER-AQ Field Experiment, Houston 2013. Atmos. Chem. Phys. 2016, 16, 14463-14474. [CrossRef]

7. Wang, T.; Xue, L.; Brimblecombe, P.; Lam, Y.; Li, L.; Zhang, L. Ozone pollution in China: A review of concentrations, meteorological influences, chemical precursors, and effects. Sci. Total Environ. 2017, 575, 1582-1596. [CrossRef]

8. Jacob, D.; Horowitz, L.W.; Munger, J.; Heikes, B.G.; Dickerson, R.; Artz, R.; Keene, W.C. Seasonal transition from NOx- to hydrocarbon-limited conditions for ozone production over the eastern United States in September. J. Geophys. Res. Space Phys. 1995, 100, 9315-9324. [CrossRef]

9. Li, L.; An, J.; Shi, Y.; Zhou, M.; Yan, R.; Huang, C.; Wang, H.; Lou, S.; Wang, Q.; Lu, Q.; et al. Source apportionment of surface ozone in the Yangtze River Delta, China in the summer of 2013. Atmos. Environ. 2016, 144, 194-207. [CrossRef]

10. Jin, X.; Holloway, T. Spatial and temporal variability of ozone sensitivity over China observed from the Ozone Monitoring Instrument: Ozone Sensitivity over China. J. Geophys. Res. Atmos. 2015, 120, 7229-7246. [CrossRef]

11. Wu, R.; Xie, S. Spatial Distribution of Ozone Formation in China Derived from Emissions of Speciated Volatile Organic Compounds. Environ. Sci. Technol. 2017, 51, 2574-2583. [CrossRef]

12. Lyu, X.; Liu, M.; Guo, H.; Ling, Z.; Wang, Y.; Louie, P.; Luk, C. Spatiotemporal variation of ozone precursors and ozone formation in Hong Kong: Grid field measurement and modelling study. Sci. Total. Environ. 2016, 569, 1341-1349. [CrossRef] [PubMed]

13. Ye, L.; Wang, X.; Fan, S.; Chen, W.; Chang, M.; Zhou, S.; Wu, Z.; Fan, Q. Photochemical indicators of ozone sensitivity: Application in the Pearl River Delta, China. Front. Environ. Sci. Eng. 2016, 10, 15. [CrossRef]

14. Shao, M.; Zhang, Y.; Zeng, L.; Tang, X.; Zhang, J.; Zhong, L.; Wang, B. Ground-level ozone in the Pearl River Delta and the roles of VOC and NOx in its pro-duction. J. Environ. Manag. 2009, 90, 512-518. [CrossRef] [PubMed]

15. Ou, J.; Yuan, Z.; Zheng, J.; Huang, Z.; Shao, M.; Li, Z.; Huang, X.; Guo, H.; Louie, P.K.K. Ambient Ozone Control in a Photochemically Active Region: Short-Term Despiking or Long-Term Attainment? Environ. Sci. Technol. 2016, 50, 5720-5728. [CrossRef] [PubMed]

16. Wang, N.; Lyu, X.; Deng, X.; Huang, X.; Jiang, F.; Ding, A. Aggravating $\mathrm{O}_{3}$ pollution due to NOx emission control in eastern China. Sci. Total. Environ. 2019, 677, 732-744. [CrossRef] [PubMed]

17. Kuo, Y.; Chiu, C.; Yu, H. Influences of ambient air pollutants and meteorological conditions on ozone variations in Kaohsiung, Taiwan. Stoch. Environ. Res. Risk Assess. 2014, 29, 1037-1050. [CrossRef]

18. Martins, D.; Stauffer, R.; Thompson, A.; Knepp, T.; Pippin, M. Surface ozone at a coastal suburban site in 2009 and 2010 : Relationships to chemical and meteorological processes. J. Geophys. Res. Space Phys. 2012, 117, 1156-1163. [CrossRef]

19. Zheng, J.; Shao, M.; Che, W.; Zhang, L.; Zhong, L.; Zhang, Y.; Streets, D. Speciated VOC Emission Inventory and Spatial Patterns of Ozone Formation Potential in the Pearl River Delta, China. Environ. Sci. Technol. 2009, 43, 8580-8586. [CrossRef] [PubMed]

20. Henneman, L.; Shen, H.; Liu, C.; Hu, Y.; Mulholland, J.; Russell, A. Responses in Ozone and Its Production Efficiency Attributable to Recent and Future Emissions Changes in the Eastern United States. Environ. Sci. Technol. 2017, 51, 13797-13805. [CrossRef] [PubMed]

21. Sharma, A.; Ojha, N.; Pozzer, A.; Mar, K.; Beig, G.; Lelieveld, J.; Gunthe, S. WRF-Chem simulated surface ozone over south Asia during the pre-monsoon: Effects of emission inventories and chemical mechanisms. Atmos. Chem. Phys. Discuss. 2017, 17, 14393-14413. [CrossRef]

22. Buysse, C.; Munyan, J.; Bailey, C.; Kotsakis, A.; Sagona, J.; Esperanza, A.; Pusede, S. On the effect of upwind emission controls on ozone in Sequoia National Park. Atmos. Chem. Phys. Discuss. 2018, 18, 17061-17076. [CrossRef]

23. Shu, L.; Wang, T.; Xie, M.; Li, M.; Zhao, M.; Zhang, M.; Zhao, X. Episode study of fine particle and ozone during the CAPUM-YRD over Yangtze River Delta of China: Characteristics and source attribution. Atmos. Environ. 2019, 203, 87-101. [CrossRef]

24. Li, Y.; Lau, K.; Fung, J.H.; Zheng, J.; Zhong, L.; Louie, P. Ozone source apportionment (OSAT) to differentiate local regional and super-regional source contributions in the Pearl River Delta region, China. J. Geophys. Res. Atmos. 2012, 117, 1276-1285. [CrossRef]

25. Kemball-Cook, S.; Parrish, D.; Ryerson, T.; Nopmongcol, U.; Johnson, J.; Tai, E.; Yarwood, G. Contributions of regional transport and local sources to ozone exceedances in Houston and Dallas: Comparison of results from a photochemical grid model to aircraft and surface measurements. J. Geophys. Res. Space Phys. 2009, 114, 1354-1362. [CrossRef] 
26. Li, Y.; Lau, A.; Fung, J.; Ma, H.; Tse, Y. Systematic evaluation of ozone control policies using an Ozone Source Apportionment method. Atmos. Environ. 2013, 76, 136-146. [CrossRef]

27. Ambrose, J.; Reidmiller, D.; Jaffe, D. Causes of high O in the lower free troposphere over the Pacific Northwest as observed at the Mt. Bachelor Observatory. Atmos. Environ. 2011, 45, 5302-5315. [CrossRef]

28. Yang, L.; Luo, H.; Yuan, Z.; Zheng, J.; Huang, Z.; Li, C.; Lin, X.; Louie, P.; Chen, D.; Bian, Y. Quantitative impacts of meteorology and precursor emission changes on the long-term trend of ambient ozone over the Pearl River Delta, China, and implications for ozone control strategy. Atmos. Chem. Phys. Discuss. 2019, 19, 12901-12916. [CrossRef]

29. Pacifko, F.J. Isoprene emissions and climate. Atmos. Environ. 2009, 43, 6121-6135. [CrossRef]

30. Folberth, G.; Hauglustaine, D.; Lathière, J.; Brocheton, F. Impact of biogenic hydrocarbons on tropospheric chemistry: Results from a global chemistry-climate model. Atmos. Chem. Phys. 2005, 5, 1267-1280. [CrossRef]

31. Cleary, P.; Wooldridge, P.; Millet, D.; McKay, M.; Goldstein, A.; Cohen, R. Observations of total peroxy nitrates and aldehydes: Measurement interpretation and inference of OH radical concentrations. Atmos. Chem. Phys. Discuss. 2007, 7, 1947-1960. [CrossRef]

32. Fu, T.; Zheng, Y.; Paulot, F.; Mao, J.; Yantosca, R.M. Positive but variable sensitivity of August surface ozone to large-scale warming in the southeast United States. Nat. Clim. Chang. 2015, 5, 454-458. [CrossRef]

33. Jia, L.; Xu, Y. Effects of Relative Humidity on Ozone and Secondary Organic Aerosol Formation from the Photooxidation of Benzene and Ethylbenzene. Aerosol Sci. Technol. 2013, 48, 1-12. [CrossRef]

34. Kavassalis, S.C.; Murphy, J.G. Understanding ozone-meteorology correlations: A role for dry deposition. Geophys. Res. Lett. 2017, 44, 2922-2931. [CrossRef]

35. Seo, J.; Youn, D.; Kim, J.; Lee, H. Extensive spatio-temporal analyses of surface ozone and related meteorological variables in South Korea for 1999-2010. Atmos. Chem. Phys. 2013, 14, 1191-1238. [CrossRef]

36. Zheng, J.; Swall, L.; Cox, W.; Davis, J.M. Interannual variation in meteorologically adjusted ozone levels in the eastern United States: A comparison of two approaches. Atmos. Environ. 2007, 41, 705-716. [CrossRef]

37. Rao, S.T.; Zalewsky, E.; Zurbenko, I. Determining Temporal and Spatial Variations in Ozone Air Quality. J. Air Waste Manag. Assoc. 1995, 45, 57-61. [CrossRef] [PubMed]

38. Rao, T.; Zurbenko, G. Detecting and Tracking Changes in Ozone Air Quality. Air Waste 1994, 44, 1089-1092. [CrossRef]

39. Milanchus, M.; Rao, S.; Zurbenko, I. Evaluating the effectiveness of ozone management efforts in the presence of mete-orological variability. J. Air Waste Manag. Assoc. 1998, 48, 201-215. [CrossRef] [PubMed]

40. Eskridge, E.; Ku, Y.; Rao, T.; Porter, S.; Zurbenko, G. Separating Different Scales of Motion in Time Series of Meteorological Variables. Bull. Am. Meteorol. Soc. 1997, 78, 1473-1483. [CrossRef]

41. Flaum, B.; Rao, T.; Zurbenko, G. Moderating the Influence of Meteorological Conditions on Ambient Ozone Concentrations. J. Air Waste Manag. Assoc. 1996, 46, 35-46. [CrossRef]

42. Wise, E.; Comrie, A. Extending the Kolmogorov-Zurbenko Filter: Application to Ozone, Particulate Matter, and Meteor-ological Trends. J. Air Waste Manag. Assoc. 2005, 55, 1208-1216. [CrossRef]

43. Liu, Q.; Xie, W.; Xia, J. Using Semivariogram and Moran's I Techniques to Evaluate Spatial Distribution of Soil Micro-nutrients. Commun. Soil Sci. Plant Anal. 2013, 44, 1182-1192. [CrossRef]

44. Huo, N.; Li, H.; Sun, F.; Zhou, D.; Li, G. Combining Geostatistics with Moran's I Analysis for Mapping Soil Heavy Metals in Beijing, China. Int. J. Environ. Res. Public Health 2012, 9, 995-1017. [CrossRef] [PubMed]

45. Zhang, C.; Luo, L.; Xu, W.; Ledwith, V. Use of local Moran's I and GIS to identify pollution hotspots of Pb in urban soils of Galway, Ireland. Sci. Total. Environ. 2008, 398, 212-221. [CrossRef]

46. Report on the State of Guangdong Provinccal Environment of 2017. Available online: http://gdee.gd.gov.cn/protect/P0201806 /P020180620/P020180620631772750308.pdf (accessed on 17 February 2021).

47. China Meteorological Data Service Center. 2019. Available online: http:/ / data.cma.cn/ (accessed on 17 February 2021).

48. Sillman, S.; Samson, P. Impact of temperature on oxidant photochemistry in urban, polluted rural and remote environments. J. Geophys. Res. Space Phys. 1995, 100, 11497-11508. [CrossRef]

49. Olszyna, K.; Luria, M.; Meagher, J. The correlation of temperature and rural ozone levels in southeastern U.S.A. Atmos. Environ. 1997, 31, 3011-3022. [CrossRef]

50. Young, C.; Washenfelder, R.; Roberts, J.; Mielke, L.; Osthoff, H.; Tsai, C.; Pikelnaya, O.; Stutz, J.; Veres, P.; Cochran, A.; et al. Vertically Resolved Measurements of Nighttime Radical Reservoirs in Los Angeles and Their Contribution to the Urban Radical Budget. Environ. Sci. Technol. 2012, 46, 10965-10973. [CrossRef]

51. Xiong, J.; Wei, W.; Huang, S.; Zhang, Y. Association between the Emission Rate and Temperature for Chemical Pollutants in Building Materials: General Correlation and Understanding. Environ. Sci. Technol. 2013, 47, 8540-8547. [CrossRef]

52. Ormeño, E.; Gentner, D.; Fares, S.; Karlik, J.; Park, J.; Goldstein, A. Sesquiterpenoid Emissions from Agricultural Crops: Correlations to Monoterpenoid Emissions an-d Leaf Terpene Content. Environ. Sci. Technol. 2010, 44, 3758-3764. [CrossRef]

53. Xue, L.; Wang, T.; Louie, P.; Luk, C.W.; Blake, D.; Xu, Z. Increasing External Effects Negate Local Efforts to Control Ozone Air Pollution: A Case Study of Hong Kong and Implications for Other Chinese Cities. Environ. Sci. Technol. 2014, 48, 10769-10775. [CrossRef] 